рассказать о истории своего города или о достопримечательностях своей страны..., что формирует высокий уровень социокультурной компетенции.» [4: 74]

В настоящее время в интернете можно найти список виртуальных экскурсий, которые тоже можно использовать в работе с иностранными обучающимися. [5] Разнообразие предоставляемой информации способствует интенсификации процесса обучения, эффективной адаптации иностранного контингента к дистанционному формату изучения предоставляемого на занятиях материала.

$$
* * *
$$

1. Касарова В.Г., Широкова О.А. Экскурсии по Москве. Учебное пособие для преподавателей подготовительного факультета для иностранных граждан. - М.: МАДИ, 2020. - 36 с.

2. Касарова В.Г., Ежовкина О.А. Использование учебного пособия «Экскурсии по Москве» преподавателями подготовительного факультета МАДИ в работе по проведению экскурсий для иностранных обучающихся / Международное образование и сотрудничество. Сборник научных трудов VIII Международной научно-практической конференции «Профессионально направленное обучение русскому языку иностранных граждан. Москва, 30 апреля 2021 года - М.: Техполиграфцентр, 2021. - С. 135-138.

3. Шишкина И.В. Организация и проведение лингвокультурологических экскурсий как одно из наиболее действенных средств повышения эффективности социокультурной адаптации иностранных студентов подготовительного факультета к условиям жизни и обучения в российских вузах // Международное образование и сотрудничество. Сборник научных трудов. Вып. №12. М.: ТехПолиграфЦентр, 2018. С.171-177.

4. Касарова В.Г., Кременецкая Л.С. Использование практикума «Гуляем по Москве» на занятиях по русскому языку как иностранному для совершенствования навыков речевой деятельности // Международное образование и сотрудничество. Сборник научных трудов по материалам VI международной научно-практической конференции. М.: ТехПолиграфЦентр, 2019. - С.71-75.

5. Список ссылок на виртуальные экскурсии по музеям России - [Электронный ресурс]. - Российская Федерация. - Режим доступа: http://mirmol.ru/blogs/spisok-ssylok-na-virtualnye-jekskursii-pomuzejam-rossii/ (дата обращения: 29.07.2021)

\title{
Касарова В.Г. \\ День Победы: сценарий проведения урока в иностранной аудитории
}

(Россия, Москва)

doi: $10.18411 / \mathrm{j}-08-2021-40$

\section{Аннотация}

В статье дается примерный сценарий урока для иностранных учащихся, который посвящен одному из важнейших праздников в России - Дню Победы. Автор статьи подробно останавливается на акцентах, которые необходимо обозначить на занятии в иностранной аудитории. Предлагается познакомить иностранных учащихся подготовительного факультета с соответствующей лексикой, остановиться на исторических деталях, показать необходимые фото и видеокадры. Информация статьи актуальна для иностранцев, интересующихся русским языком, русской историей и культурой. Представленная информация поможет преподавателям организовать занятие в иностранной аудитории.

Ключевые слова: День Победы, праздник, иностранные учащиеся, сценарий урока, лексика, русский язык как иностранный, русская история и культура, организовать занятие, исторические детали.

\section{Abstract}

The article provides an approximate script for a lesson for foreign students, which is dedicated to one of the most important holidays in Russia - Victory Day. The author of the article dwells in detail on the accents that need to be outlined in a lesson in a foreign 
audience. It is proposed to acquaint foreign students of the preparatory faculty with the appropriate vocabulary, dwell on historical details, show the necessary photos and video frames. The information in the article is relevant for foreigners interested in the Russian language, Russian history and culture. The information provided will help teachers organize a lesson in a foreign audience.

Keywords: Victory Day, holiday, foreign students, lesson script, vocabulary, Russian as a foreign language, Russian history and culture, organize a lesson, historical details.

В период обучения на подготовительном факультете иностранные студенты знакомятся с историей и культурой России. Это происходит на занятиях по русскому языку и истории. Практически в каждом учебнике для иностранных учащихся есть информация о различных российских праздниках. Исходя из нашего опыта работы в иностранной аудитории, мы можем сказать, что данная тема вызывает большой интерес у иностранных обучающихся. Особое место в этой теме занимает важнейший российский праздник - День Победы. Преподаватели на уроках рассказывают иностранным обучающимся об истории данного праздника и о его праздновании. [1: 292]

Предлагаем макет возможного проведения занятия по русскому языку или истории, посвященного Дню Победы. В начале урока мы советуем объяснить учащимся, что такое «государственный праздник», после чего написать цифрами и буквами дату: «9 Мая, Девятое Мая - День Победы», «Девятого Мая в России отмечают День Победы.» Потом мы предлагаем подробно остановиться на глаголах «отмечать» - «отметить» что?, «отмечаться», показав все их формы в настоящем, прошедшем и будущем времени. Также мы советуем познакомить учащихся с отглагольным существительным «отмечание» чего? («отмечание Дня Победы»). Далее предлагается рассказать, где отмечается этот праздник, приведя примеры. Например, «День Победы - это большой праздник. Этот праздник отмечают в России, Белоруссии, Армении, Азербайджане, Грузии, Казахстане, Туркменистане, Узбекистане, Молдавии и других странах (можно назвать большее количество стран, это делается по усмотрению преподавателя. Если в группе есть учащиеся из стран бывшего СССР, мы рекомендуем обозначить эти страны). В этот момент можно показать учащимся называемые страны на географической карте.

После этого мы советуем рассказать об истории праздника, при этом желательно во время рассказа подробно останавливаться на новой лексике, предлагая учащимся записывать новые лексические единицы. Например, «Великая Отечественная война (ВОВ) началась 22 июня 1941 года и закончилась 9 мая 1945 года. 9 мая 1945 года война закончилась в России, в Европе война закончилась 8 мая 1945 года. Даты окончания войны разные, потому что между Россией и Европой была разница во времени в один час. Поэтому сейчас в России праздник отмечают 9 мая, а в Европе 8 мая. Великая Отечественная война - это война между СССР и фашистской (нацистской) Германией и ее союзниками в Европе. СССР - это Союз Советских социалистических республик или Советский Союз. Великая Отечественная война является частью Второй мировой войны. Война закончилась победой СССР. Празднование Дня Победы установил специальный документ. Этот документ назывался «Указ Президиума Верховного Совета СССР». Это был приказ И.В. Сталина». Мы рекомендуем показать фотографии И.В. Сталина и данного указа, при этом в нескольких словах пояснить или напомнить, что И.В. Сталин был руководителем СССР в этот период. Далее следует обратить внимание учащихся на глагольную связку «праздновать» - «отпраздновать» что?, отметив, что данные глаголы являются синонимами уже представленным ранее глаголам «отмечать» - «отметить». Также, на наш взгляд, следует привести примеры использования данного глагола: «Каждый год мы празднуем День Победы 9 мая». От глаголов «праздновать» - 
«отпраздновать» можно образовать существительное «празднование» чего? («празднование Дня Победы»).

Затем мы предлагаем рассказать иностранным учащимся, как в России отмечают День Победы, кого поздравляют с этим праздником, как поздравляют, что при этом говорят и т.д. В процессе рассказа мы рекомендуем записывать новые лексические и грамматические единицы, подкрепляя их примерами. [2: 24] Например, можно продолжить рассказ по данной схеме: «Празднование Дня победы. Обязательно на Красной площади проводят парад с участием военной техники». Мы обращаем внимание учащихся на глагольную пару «проводить» - «провести» что? парад и на отглагольное слово «проведение» чего?, «проведение парада на Красной площади в центре Москвы». Также мы используем глаголы «возлагать» - «возложить» что? цветы, венки к памятникам. После этого обращаем внимание учащихся на новые слова «венок» - «венки» и отглагольное существительное «возложение» чего? венков. В процессе введения этих глаголов и существительных мы советуем показать фотографии и видео праздничного парада и возложения венков, например, президента России, гостей парада, ветеранов, жителей и гостей Москвы. Можно показать фотографии и видеокадры праздника из других городов и стран.

Необходимы для изучения темы также глаголы «поздравлять» - «поздравить» кого?, отглагольное существительное «поздравление» кого?, «поздравление ветеранов Великой Отечественной войны». Таким образом, мы также вводим новые слова «ветеран» - «ветераны», сопроводив их соответствующим фото и/или видеорядом и объяснениями, например, «Ветераны - это люди, которые участвовали в войне, воевали и защищали нашу родину» [3: 61]. Мы советуем также рассказать иностранным учащимся, что обычно в этот день ветеранам дарят цветы, другие подарки, поздравляют их с праздником, с 9 мая. Ветераны в этот день рассказывают свои истории, вспоминают, какой страшной была война.

Мы считаем, что необходимо также остановиться на том, что с 2012 года в России появилась следующая традиция - проводить акцию «Бессмертный полк». Здесь мы используем уже известные учащимся глаголы «проводить» - «провести» что? в сочетании со словом «акция», «провести акцию, которая называется «Бессмертный полк». Следует при этом пояснить, что обозначают слова «бессмертный», например, «тот, кто не умер, тот, кто жив, живой», слово «полк», например, «это большая группа солдат». После подробных пояснений необходимо рассказать, что обозначает эта акция, кто и зачем принимает в ней участие. Далее нам представляется целесообразным показать фото и видео, как проходит эта акция. Обычно подобные фотографии, а особенно видео производят на иностранных учащихся большое впечатление.

Мы предлагаем также рассказать учащимся о таком символе 9 мая, как георгиевская лента или ленточка, показав фотографии и объяснив, что ее можно купить в магазине или получить бесплатно на улице, где ее можно носить, пояснив, что этот символ является памятью о защитниках нашей страны.

Следующими, необходимыми, на наш взгляд, глаголами являются «запускать» «запустить» что?, «запустить салют, фейерверк», отглагольное существительное «запуск» чего? («запуск салюта», «запуск фейерверка»). Данные глаголы также лучше сопроводить соответствующими фотографиями и видеорядом.

В заключении мы предлагаем добавить еще несколько глаголов, например, «помнить» кого? что?, «Мы помним Великую Отечественную войну», «Мы помним солдат», «Мы помним ветеранов войны» [4: 96]. Также нам представляется важным введение глагола «гордиться» кем? чем?, «Мы гордимся солдатами.», «Мы гордимся нашей страной, нашей родиной.», «Мы гордимся ветеранами.» и т.д. 
Мы советуем в процессе проведения занятия посвященного Дню Победы активно использовать фотографии и видеоматериалы. В конце урока можно показать видео с песней «День Победы».

Проведение занятий, посвященных Великой Отечественной войне и Дню Победы, нам представляется чрезвычайно важным и необходимым в иностранной аудитории, поскольку зачастую иностранные граждане дезориентированы и дезинформированы информацией из интернета. В настоящее время можно прочитать больше количество недостоверной информации, фальсификации на тему войны и Победы. К тому же, как показывает наш опыт работы в иностранной аудитории, в зарубежных учебниках и учебных пособиях теме Второй мировой войны, Великой Отечественной войны, да и вообще истории СССР и России, уделяется не очень много внимания. Поэтому у преподавателей, работающих с иностранными учащимися, есть возможность рассказать им об этом важном периоде истории.

$$
* * *
$$

1. Касарова В.Г., Филипская Т.А. Методика работы с текстами по истории России в дистанционном формате (из опыта работы) // Международное образование и сотрудничество. Сборник научных трудов VIII Международной научно-практической конференции «Профессионально направленное обучение русскому языку иностранных граждан. Москва, 30 апреля 2021 года - М.: Техполиграфцентр, 2021. - С. 292-297.

2. Касарова В.Г. К проблеме обучения иностранных учащихся на этапе довузовской подготовки в дистанционно формате // Современное педагогическое образование. - 2021. - № 4. - С.24-27.

3. Касарова В.Г. О некоторых аспектах преподавания русского языка как иностранного // Материалы XXIV международной научно-практической конференции Наука в современном информационном обществе. Science in the modern information society XXIV 9-10 ноября 2020 г. North Charleston, USA. - C-60-65.

4. Касарова В.Г., Кременецкая Л.С., Никишина Ю.В. Подготовка специалистов для стран Центральной Азии // Современное педагогическое образование. - М.: Русайнс, 2018. - №1. С. 9597.

\section{Латышева В.Л., Федина Е.А. \\ Необходимость и актуальность профориентационной работы вузов в современных условиях}

doi: $10.18411 / \mathrm{j}-08-2021-41$

Юридический Институт ИГУ

(Россия, Иркутск)

\section{Аннотация}

Цель статьи - анализ трудностей и актуальных направлений организации профориентационной работы вузов в современных условиях и обоснование роли вузов в повышении эффективности осознанного выбора будущей профессии среди абитуриентов. В статье также рассматриваются основные направления профориентационной деятельности в вузе, направленные на сохранение его конкурентоспособности.

Ключевые слова: профориентационная работа, абитуриент, вуз, выбор профессии, профессиональное самоопределение, довузовское образование.

\section{Abstract}

Purpose of the article - analysis of difficulties and current trends in the organization of career guidance in modern conditions and the rationale for the role of the universities in improving to make conscious choice of a future profession. The article also discusses the main directions of career guidance activities at the university, aimed at preserving its competitiveness.

Keywords: career guidance, applicant, university, choice of profession, professional self-determination, pre-university education. 